\title{
Desperation of Demographic Change in the Health Sector in Germany: Necessary Strategy Orientation for Medical Practices in the Countryside
}

\author{
Sabine Abbasi \\ Mendel University, Brno, Czech Republic
}

\begin{abstract}
The demographic development in Germany affects the entire health care system. The fact is that more and more people are getting older and older and due to the increasing multi-morbidity in old age, more and more health care services are needed. But there are fewer and fewer professionals providing these services. This phenomenon can be observed both in the medical, nursing, and social fields. The shortage of doctors and skilled workers that has become apparent in recent years-especially in rural areas-has led to hospitals, medical care centers (MVZ), and medical practices searching for qualified personnel to use the usual acquisition mechanisms (advertisements in daily and professional newspapers, recruiting staff) due to the unsatisfactory results. The alternatives require a high degree of pragmatism. This article demonstrates the importance of strategic alignment in HR marketing of rural medical practices and identifies concrete ways to retain existing employees and position them as an attractive employer for potential new employees.
\end{abstract}

Keywords: management, human resources, labour demand

\section{Introduction}

The generation from the year 1955, the so-called baby boomers, retires from 2020 (Bruch, Kunze, \& Böhm, 2010, p. 45) and will increasingly take advantage of health and long-term care with a sharp increase in life expectancy. In the medical sector, in contrast to this strong increase in demand on the supply side, there has been a decline in many areas: Birthrates are declining (Federal Office of Statistics, 2011, p. 11), as the number of high school graduates (Conference of the Minister of Education and Cultural Affairs of the federalstates in the Federal Republic of Germany, 2005) from which junior medical staff could be recruited or the number of vocational raining completed health sector. The skilled workers with successfully completed vocational training in the health sector are also increasingly following the call of lucrative positions in other non-medical areas or abroad and are thus for the time being lost to the German health system as a medical specialist. This phenomenon is occuring in whole Germany eminently in the rural sector. Many rural medical practices are not able to treat all patients due to the lack of skilled health care workers. Another development is the "feminization" of medic ine: $70 \%$ of undergraduate medical students and $60 \%$ of graduates are female, as are $41.5 \%$ of practicing physicians compared to 33\% in 1991 (Meyer-Radtke, 2009). Because job and family

Sabine Abbasi, LL.B, M.Sc., university lecturer, Ph.D. student at Faculty of Economics and Management, Mendel University, Brno, Czech Republic. 
planning often can not be reconciled, many physicians fall in the first years of their career for a long time as a doctor, if there are no family-friendly working conditions and the decision to start a family is made (Kopetsch, 2010, p. 102). The same is true of medical professionals. In addition, there is a greater desire across gender boundaries for a balance between work and private life-work-life-balance (trendence, 2011)—which is often incompatible with everyday hospital life and regular working hours in the health care sector. Opening hours of kindergardens and other institutions are not fitting to the regular working hours in the health care sector. In the nursing sector, the training institutes, on the one hand, face stagnating registration numbers (Görres, 2010); on the other hand, the typical nursing students are often no longer adequately schooled (Blum, 2006). At the same time, the attractiveness of the nursing profession drops as a result of continuous high demands on a subjective basis perceived underpayment (Görres, 2010). An ever-increasing number of nursing staff leaving their institution (Hasselhorn, Schmidt, Borchart, Galatsch, \& Dichter, 2006) also contributes to their perceived attractiveness. An additional undesirable side effect is that qualified and desperately needed personnel are thus eliminated; so the trend described above is still increasing. In addition to these demographic components, the desire of many young professionals born in 1981, the so-called Generation Y (Parment, 2009, p. 13), to live and work in a larger city, also plays a major role. Income opportunity, infrastructure, job offers, and cultural institutions are much better in cities than in the countryside. In particular, it makes it difficult for rural hospitals and medical practices to acquire junior medical staff due to the supposedly lower living and living quality in smaller cities. A survey conducted by the German Chamber of Commerce and Industry has shown that $65 \%$ of companies in the health care sector see the shortage of skilled workers as the greatest risk to their economic development (DIHK, 2011, p. 48). Also, the demands on advanced education in health care sector shows that the young professionals want to succeed. Discrepancy to this is that only few professionals are able to use the passed advanced education. A non-representative telephone survey of 162 hospital directors in August/September 2011 shows a clear, although alike not representative tendency shown. The majority of the 40 people who took part in the survey had a very pessimistic assessment of the question, "how easy is it to fill vacant medical posts?" This is in line with the results of a diffusion kurtosis imaging (DKI) study: "At the beginning of 2010, around three quarters of hospitals (74.2\%) had problems filling vacancies in the medical service" (Blum \& Löffert, 2010, p. 126). The established doctors face the same problem, but this is about the succession or the transfer of practice. Do not find successors in having to return their National Health Service (NHS) doctor office to the and their patients, who have cared for them in their long Association of Statutory Health Insurance Physicians (AHIP) professional life, then have to look for a new doctor. For both areas, it is aggravating that in 2009, at $19.6 \%$, almost every fifth contract doctor was 60 years old or older, but only $16.6 \%$ of doctors in Germany were younger than 35 years old (Kopetsch, 2010, p. 24).

\section{Assigned Measures: With Suitability Against the Shortage of Skilled Workers}

For many institutions, the problem arose or became virulent in the short term. Likewise at short notice, solution measures usually aim to limit damage. In many places, the use of HR consultants, who can only manage the shortage, is one of the "classic" activities to tackle the shortage of skilled workers. Another short-term measure is the switching of personnel search ads in relevant specialist publications, which costs up to 13,000 euros for a full-page color display (Deutscher Ärzteverlag, 2012, p. 5); plus the cost of creating an advertising agency. However, if a total of 100-300 jobs are offered on 50-60 pages job market, the response is often unsatisfactory from the view point of the advertisers, especially since these publications are mostly read in 
the clinics and they arrive very late at individual doctors or specialized staff in the circulation procedure (hierarchy).

"Employees recruit employees" is another form of acquisition efforts for skilled personnel. Employees receive a bonus for successful placement of a candidate. Presenceat university events (e.g., in the application for junior doctors for the practical year) have gained in importance as well as the integration of foreign doctors and professionals who have to be simplified with language courses and organizational assistance (assistance with public authorities and housing mediation) with the start as a specialist in Germany. Currently, a great planty of health care workers and professionals in Germany are foreigners from other European countries (e.g., Poland and Romania). To get these skilled workers from abroad also needs advertisement in these countries and knowledge of the respective job market. To sumup, these ad hoc measures cannot solve structural problems (as mentioned, e.g., demographic change, working hours, and also payment in health care sector) and therefore a more far-sighted and more strategic approach should be considered.

\section{Strategic Measures}

Personnel marketing means "taking the needs and expectations of current and future employees as the starting point for human resource management to develop employment relationships that are most beneficial to both the company and the employees" (Staffelbach, 1995, p. 144). It is less a function than a function to be understood as a model that takes into account the "effects of corporate activities on potential and current employees". The term thus has an internal and an external component. From this, it becomes clear that the employees are on the focus of personnel marketing. If it is referred to current employees, it is a matter of internal personnel marketing. If the future employee is in the foreground, it is a matter of external personnel marketing (D. Loffing \& C. Loffing, 2010, p. 63).

\section{Internal Personnel Mark eting}

Internal HR marketing aims to bind and motivate the employees already employed in the company to the company. This has the distinct advantage that it is better to keep staff in the company than to recruit them. With the awareness that most people nowadays want to do work themselves; money and flextime are no longer sufficient incentives to retain employees. Instead, measures of internal HR marketing aim to bind employees as emotionally as possible to the company. This is especially successful when employees identify with the values of the company and can thus realize their own work. The three most effective screws a company can turn are:

(1) Communicate company values to employees (employer branding);

(2) Create identification possibilities with the company;

(3) Increase commitment.

Increased commitment and clearly communicated corporate values (which can be experienced through your corporate culture and your actions) increase the likelihood of an emotional attachment to the company. This actively lowers the turnover rate, and increases loyalty to the company and the satisfaction of current employees in their workplace. Accordingly, internal personnel marketing has an increased psychological impact and is therefore particularly complex and extensive. In addition to personal marketing instruments, instruments of internal communication and corporate communication can also influence this.

In essence, internal HR marketing pursues the following goals (D. Loffing \& C. Loffing, 2010, p. 63):

(1) High workmotivation; 
(2) High job satisfaction;

(3) High identif ication with the company;

(4) Long-term commitment to the company.

Regular employee surveys are an important tool for timely and customized internal HR marketing. They inform about the degree of achievement of these goals and help to be able to take counter measures. They should be carried out anonymously by neutral market research companies in order to ensure the highest possible degree of responsiveness. It is important to coordinate with the employee representation or the works council as well as timely and comprehensive information of the employees about the planned action. The evaluation of this survey then provides the clues for further activities. Surveys that are sporadic and not regular often lead to insecurity and rumors in the workforce, and exclude those who have been with them for a short time. In addition, the values are missing to carry out analyzes.

\section{External Personnel Marketing}

Recruiting for new employees has a very long tradition that still exists today. Personnel marketing no longer refers only to the external labor market, but increasingly also to the internal (employee) market. Nonetheless, it is essential, especially today, to position yourself positively as a company in the resource market - and also in the health care sector-and stand out from the competition. The goal to be pursued is to reach as many suitably qualified applicants as possible in order to increase the candidate experience and minimize recruitment costs. The three most effective screws a company can turn are:

(1) Increase aw areness;

(2) Create a positive employer image;

(3) Communicate company values to future applic ants (employer branding).

Only then can companies ensure that they attract enough applicants and that they also fit in the best possible way in the company. By integrating the corporate values into the communication and presentation of the company to the outside, a preselection of the applic ants already takes place.

The goals of external HR marketing can be listed as follows (D. Loffing \& C. Loffing, 2010, p. 63):

(1) High profile;

(2) Distinctive "brand";

(3) Attractive external impact as a company and employer;

(4) Recruiting suitable employees.

The prerequisite is a needs-based and target-group-specific approach. The occupation of a job vacancy is not the primary goal, but rather the creation of the employer's image as positive as possible and anchored in the minds of the target group. The thus conveyed positive overall impression materializes itself to the prospective customer or applicant for example in the form of a structured and transparent employee selection process.

This is also the case with the working atmosphere and the internal organizational culture, which is communicated at each contact (Internet, e-mail, letter, fax, telephone call, and conversation). In the mediumterm, this also helps to optimize the costs of recruitment and improves the quantity and quality of incoming applications. The job vacancies are shortened. A prerequisite for implementation is the presence of the employer in the minds of the target group. This presence can be realized at the enterprise level either through the positive role of the company as a producer of capital goods and consumer goods or providers of 
services that the members of the target group use or at least know. On a second level, this leads to the image of an employer that the public gets from him.

\section{Personnel Marketing for Health Care Institutions}

Employer branding in health care is an important tool. However, employer branding is along process that is too often equated solely with striking and original recruitment methods. But that falls short. For hospitals, institutions for people with disabilities, or old people's care to be able to send out messages that contribute positively to their employer brand, they first have to clarify how they have to position themselves internally so that they are a really attractive breadwinner for their employees.

Employer branding can only work if it is strategically approached. However, it is not nice to say that the nursing sector is facing a particular challenge. For nursing professions are not considered particularly attractive among applicants. The reasons for that are complex:

(1) Badpayment;

(2) Family unfriendly shift services;

(3) High time pressure during care;

(4) Too low personnel key;

(5) Too much bureaucracy.

However, to improve the situation in one's own company, it will not be enough for HR departments or doctors to impose on their employees a catalog of measures that grabs the well-known problems at the roots. Instead, employers have to pinpoint exactly where it actually gets stuck in the process. Otherwise, there is a great danger of acting against each other and implementing the wrong ideas. The path to a better employer brand in nursing, MVZs, and hospitals can therefore only lead through an employee survey-from the management level to the trainee. From this, HR managers can read out what their employees specifically want and need. This is in fact the same operational management is doing. Therefore, institutions of the health care system often apply the methods of operational management (for example, purchasing, logistics, process optimization, and marketing) which are standard in the industry, only with a few years delay. This also applies to the target group-specific personnel marketing: According to a study of the personnel consultancy Kienbaum Management Consultants $\mathrm{GmbH}$, this instrument is only used in 54\% of the surveyed hospitals on the other hand, however, HR marketing by the same respondents is considered to be the most significant activity for future recruitment of hospital staff, followed by financial incentives and the recruitment of foreign workers (Kienbaum Management Consultants $\mathrm{GmbH}, 2009$, p. 40). The importance of personnel marketing for the recruitment area is reflected neither in their own quality, which the respondent clinic managers classified rather mediocre for this area (Kienbaum Management Consultants GmbH, 2009, p. 25), nor in terms of staffing: Of the average of 10 employees, the surveyed hospitals in the average in the human resources department, only 2.1 employees were recruited in 2009-after 2.9 employees in 2005.

\section{Bench Marking-A Comparison With the Best}

A helpful focus shows how the HR marketing activities of the top companies from industry, commerce, services, and institutions support recruiting their off-spring and new employees. A survey, which is regularly conducted by manager magazine in cooperation with the consulting firm trendence, annually selects the most popular employers in Germany. Companies, such as Audi, BMW, Lufthansa, Porsche, and Adidas have acquired a high degree of attractiveness among the graduates of a business degree program (Werle, 2011). All 
have in common that they consistently implement the idea of personnel marketing and operate employer branding. This term (Stotz \& Wedel, 2009), which was first used in 1996, will not be further elaborated here, but only briefly described (ibid).

Just as manufacturers build and maintain their brands as personalities (classic branding), employers use employer branding as an employer to create a brand image as part of their HR marketing in order to be an attractive company for the target group of employees. At Lufthansa, as an aviation service provider, there is consequently a dedicated and target group-specific Internet presence for personnel marketing (Deutsche Lufthansa AG, 2011), which combines information with playful elements and emotionally charges the employer brand Lufthansa. Personnel marketing in these companies is characterized by the fact that it is its own area of responsibility, separate from traditional human resources management, which has its own budget (time and money) and has to achieve clearly defined goals on the market-a clear parallel to the classic product and service management service marketing. The target group elements in the market are different for potential employees after the phase of entering the profession (after school, after graduation, and after graduation), the qualification level of the applicant (lower secondary education and middle school, A-levels, and studies) and after, if it is job changer trades or returnees after maternity leave or parental leave. For existing employees, areas of activity, functions, and hierarchy levels are suitable distinguishing criteria.

Some companies also offer special programs for so-called high-potential applicants, who are willing to take on responsibility early on and are given a great deal of developmental potential (Spickschen, 2005). They are of great interest to potential employers and are often used in special programs additionally encouraged and regularly contacted with the aim of establishing the closest possible connection in order to gain him/her as a worker at a later date. These support programs exist in many companies in the context of personnel development, also for existing employees in order to bind them. The contact with interested parties is already partly in school, where there are so-called learning partnerships between educational institutions and clinics. A first exchange should take place here, with the goal of building a positive image and interest among the students. In addition to these measures for potential employees, numerous measures are also being implemented in the industry for the existing employees, which will be exemplified by the example of the German clothing manufacturer Hugo Boss, ranked Number 27 in Germany's top employer. Behind this is the philosophy that even a very professional external employer branding will remain ineffective "if new employees do not find the promise of the employer brand when they join the company and lose their initial enthusiasm" (Stotz \& Wedel, 2009 , p. 196). In order to keep the employees loyal to the company and to turn them into advocacy (ibid), Hugo Boss offers a multitude of offers, which are briefly outlined here: employee magazine, Intranet, regular feedback discussions, rapid internal information transfer from supervisors, Hugo Boss Academy for Further Education, Salary Bonus Employee Benefit Account, Art Pass for Free Museum Visit in Selected Museums of the World, Sports and Cultural Offers, Occupational Health Management, Healthy Eating, Screening and Vaccination, Family Support, Social and Conflict Consultation (ibid), and many more.

\section{Health Institutions: Concrete Measures}

Health care companies can learn from large corporations, though these have different claims and other financial opportunities. In particular, the employee-centered mental approach, which is reflected in the hitherto described personnel marketing measures, is readily applicable to clinics, medical practices, MVZ, and care facilities transferable. In any case, the concrete design must be adapted to the individual needs and possibilities 
of the respective institution. In the following, two concrete approaches are presented toget to know the needs of the target group better.

Surveys. Only those who know their target group can communicate with them on the right level in a goal-oriented manner and offer them what they really want. Surveys of the target group are a frequently used remedy for the current employees and by the graduates. As part of its graduate survey, the Westfälische Wilhelms-University in Münster regularly surveys the wishes of medical students and graduates in their first year of work. The survey from 2008 showed among other things that first of all the importance of the professional starters is a good working atmosphere, followed by the possibility of professional further qualification. Other aspects in the order of their importance: interesting work content, ability to use acquired skills, demanding work, job security, and largely independent work planning. The eighth place was followed by a high income (Westfälische Wilhelms-University Münster, 2010). These insights can be directly translated into an acquisition strategy for new employees, in which the offer made by clinics, doctors' practices, or MVZs to young professionals takes up these criteria and creatively implements them. This must then also be reflected in the communication with the target group (e.g., in information brochures and Internet appearances). On the other hand, employee surveys can also be conducted, subdivided according to different target group segments. For example, new entrants in their first permanent position should be asked different questions than long-term specialists. Employee surveys, on the one hand, reveal weaknesses, but on the other hand, allow management to take counter measures.

Expert interviews. Through the experts as a medium, the user receives information about specific issues. The experts have a special position in the social context (health care), which should be investigated. As part of a project week at the Osnabrück University of Applied Sciencesin May 2011, students with health care management backgrounds interviewed human resources managers from various clinics and health-related institutions on their assessment of the challenge of skills shortages (Osnabrück University, 2011). These findings were then collated and brain-stormed. The skills shortage was confirmed by all managers, including the increased salary requirements. In the care sector, the attractiveness of the profession and the hospital as an employer has declined sharply.

The applicants are often not qualified enough; a strong deficiency is observed in the area of specialist care. As personnel marketing measures, the classical standard methods are applied; a large part of the activities is owed to a specific need; only rarely and rarely is structured marketing operated over a longer period. Concrete HR marketing measures are day-care offers, working time models, special solutions for job-seekers, personnel development talks, and the highest possible family friendliness in various areas. For acquisitions, advertisements in the specialist press and the daily newspaper are used primarily, but also personnel consultants and public relations to create a positive image.

For the future, the personnel managers surveyed are clear that especially the smaller houses and the clinics in more rural regions need to find individual and unconventional solutions. In particular, in view of the increasing administrative burden on medical staff, more activities will soon be transferred to specially trained nurses. The general shortage of skilled workers in the health sector must be remedied by politics (education policy and health policy), but the problem of regional skills shortages by clinics, medical centers, and medical practices in the region itself.

Expert interviews: Internal personnel marketing. The greatest number of ideas via brain-storming came from the area of internal HR marketing. First and foremost were the measures to make the appreciation 
for employees clear. It was interesting that the issue of pay or salary increase does not seem to play a prominent role. More important are aspects, such as appreciation, cross-disciplinary and cross-hierarchical thinking, supervision for all, appreciation by superiors, transparent career and future planning, self-fulfillment, mentoring program for new employees, family attention, welcome package with information, employee development talks, team events, participation in the company's success, sabbatical (including parental leave), training, and much more.

Expert intervie ws: External personnel marketing. In external HR marketing, measures were essentially taken to build, promote, and maintain regular and positive contact between the interested party and the clinic. The third category career planning is not clearly assignable, as there are also some suggestions to find that are relevant for current employees can and therefore is just as much part of the internal HR marketing measures belong. For communication with the target group. For example, the media Facebook, e-cards, job apps for smartphones, attractive image with attractive slogan, possibility to stay abroad (in exchange), analog and digital greeting scards with original motives, offer internships/internships abroad, information on Youtube as well sophisticated and focused on different target groups homepage with personnel marketing focus.

\section{Discussion and Conclusions}

Even if the measures and findings listed here are not representative, they clearly indic ate the direction in which the professionalisation of health institutions must continue. Personnel development and strategic personnel marketing are necessary for the survival of a clinic, because without doctors and nurses, the patients will stay away. Money as an incentive does not really meet the primary needs of employees, whether they are current or potential employees. Finding out what they want and implementing it consistently and planned will be one of the big challenges. Like all marketing, HR marketing lives from the unique position that sets the institution apart from others. Finding them and communicating clearly to the outside and inside will be vital in the "war for talents". The new media must also be included here, because in many aspects, they are the only medium that Generation Y regularly uses.

\section{References}

Blum, K. (2006). Pflegeausbildung im Umbruch. Pflegeausbildungsstudie Deutschland (PABiS) [Nursing education in transition. Nursing education study Germany (PABiS)]. Düsseldorf: Dt. Krankenhaus-Verl.-Ges.

Blum, K., \& Löffert, S. (2010). Ärztemangel im Krankenhaus. Ausmaß, Ursachen, Gegenmaßnahmen. Forschungsgutachten im Auftrag der Deutschen Krankenhausgesellschaft (Lack of doctors in the hospital. Extent, causes, countermeasures. Research report on behalf of the German Hospital Association). Bremen: Deutsches Krankenhaus Institute.

Bruch, H., Kunze, F., \& Böhm, S. (2010). Generationen erfolgreich führen. Konzepte und Praxiserfahrungen zum Management des demografischen Wandels (Lead generations successfully. Concepts and practical experience to manage demographic chan ge). Wiesbaden: Gabler.

Conference of the Minister of Education and Cultural Affairs of the Federal States in the Federal Republic of Germany (Ed.). (2005). Prognose der Studienanfänger, Studierenden und Hochschulabsolventen bis 2020 (Forecast of undergraduates, students and graduates by 2020). Bonn: Statistic Publication.

Deutsche Lufthansa AG (Ed.). (2011). Jobs and career. Entry options. Retrieved from https://www.belufthansa.com/de Deutscher Ärzteverlag. (2012). Mediadaten. Auszug aus der Preisliste Nr. 54 (Media data. Excerpt from price list no. 54). Köln.

Deutscher Industrie-Und Handelskammertag, E. V. (DIHK) (Ed.). (2011). Wirtschaftslage und Erwartungen. Ergebnisse der DIHK-Umfrage bei den Industrie- und Handelskammern (Economic situation and expectations. Results of the DIHK survey at the Chambers of Commerce and Industry). Berlin.

Federal Office of Statistics (Ed.). (2011). Demografischer Wandel. Bevölkerungs- und Haushaltsentwicklung im Bund und in den Ländern (Demographic change. Population and housing development in the Federal Government and in the Länder). Wiesbaden: Statistisches Bundesamt. 
Görres, S. (2010). Imagekampagne für Pflegeberufe auf der Grundlage empirisch gesicherter Daten. Einstellungen von Schüler/innen zur möglichen Ergreifung eines Pflegeberufes. Ergebnisbericht (Image campaign for nursing professions based on empirically verified data. Attitudes of students to the possible adoption of a nursing profession. Score report). Retrieved from https://www.pflegendz.de/files/content-asset/pdf-downloads/projekte/imagekampagnepflegeberufe/Image_ Abschlussbericht-Endfassung.pdf

Hasselhorn, M., Schmidt, S., Borchart, D., Galatsch, M., \& Dichter, M. (2006). Gründe von Pflegenden, ihre Einreichungen zu verlassen. Ergebnisse der Europäischen next-Studie (Reasons for nurses to leave submissions. Results of the European next study). Bergische University Wuppertal. Retrieved from http://www.google.de/url $? \mathrm{sa}=\mathrm{t} \& \mathrm{rct}=\mathrm{j} \& \mathrm{q}=\&$ esrc=s\&source=web\& $\mathrm{cd}=1 \& \mathrm{ved}=2$ ahUKEwjXxOzv8MHeAhUOZFAKHUFzAlEQFjAAegQIARAC\&url=http\%3A\%2F\%2Fwww.altenpflegeonli ne.net\%2Fcontent\%2Fdownload\%2F146776\%2F2922740\%2Ffile\%2Fap_09_10_pflegepraxis_next.pdf\&usg=AOvVaw1xM JHCLCnCi-UFGcpFRUUe

Kienbaum Management Consultants GmbH (Ed.). (2009). Wertschöpfende Personalarbeit in Krankenhäusern (Value-adding personnel work in hospitals). Gummersbach.

Kopetsch, T. (2010). Dem deutschen Gesundheitswesen gehen die Ärzte aus. Studie zur Altersstruktur- und Arztzahlentwicklung (The German health service doctors go out. Study on age structure and number of physicians). Berlin: German Medical Association.

Loffing, D., \& Loffing, C. (2010). Mitarbeiterbindung ist lernbar. Praxiswissen für Führungskräfte in Gesundheitsfachberufen (Employee loy alty is learnable. Practical knowled ge for managers in healthcare professions). Berlin: Springer Medizin.

Meyer-Radtke, M. (2009). Aus Herr Doktor wird Frau Doktor (From Mr doctor becomes Mrs doctor). Retrieved from https://www.zeit.de/karriere/beruf/2009-12/feminisierungmedizin

Osnabrück University. (2011). Project week report. Retrieved from https://www.mabga.de/de/forschung-internationales/ forschungsprojekteforum/

Parment, A. (2009). Die Generation Y - Mitarbeiter der Zukunft. Herausforderung und Erfolgsfaktor für das Personalmanagement (The Generation Y employees of the future. Challenge and success factor for personnel management). Wiesbaden: Gabler.

Spichschen, E. (2005). Internes Unternehmertum und Recruiting von High-Potentials. Theoretische und empirische Untersuchung (Internal entrepreneurship and recruiting of high-potentials. Theoretical and empirical investigation). Wiesbaden: Dt. Univ.-Verlag.

Staffelbach, B. (1995). Personalmarketing (Personal marketing). In C. Suolz (Ed.), Strategisches Personalmanagement (Strategical management) (pp. 147-158). Stuttgart: Schäffer-Poeschel.

Stotz, W., \& Wedel, A. (2009). Employer Brandig. Mit Strategie zum bevorzugten Arbeitgeber (Employer brandig. With strategy as preferred employer). München: Oldenburg.

Trendence GmbH. (2011). Berufsanfänger: Google und deutsche Konzerne als Arbeitgeber beliebt. Trendence Young Professional Barometer 2017 (Career starters: Google and German corporations are popular as employers. Trendence Young Professional Barometer 2017). Retrieved from https://www.trendence.com/presse/studie-y oung-professionals.html

Werle, K. (2011). Die beliebtesten Arbeitgeber (The most popular employers). Managermagazine, 42, 115.

Westfälische Wilhelms-University Münster. (2010). Kurzzusammenfassung erster Ergebnisse der Absolventenbefragung 2008 für das Fach Humanmedizin (Brief summary of the first results of the 2008 graduate survey for the subject Human Medicine). Retrieved from https://www.uni-muenster.de/imperia/md/content/wwu/rektorat/absolventen/bericht_kowi_2007_ins gesamt. pdf 